\title{
McDowell's New Conceptualism and the Difference between Chickens, Colours and Cardinals
}

\author{
Gersel, Johan; Thybo Jensen, Rasmus; Thaning, Morten Sørensen
}

\author{
Document Version \\ Accepted author manuscript \\ Published in: \\ Philosophical Explorations \\ DOI: \\ 10.1080/13869795.2016.1273377 \\ Publication date: \\ 2017 \\ License \\ Unspecified
}

Citation for published version (APA):

Gersel, J., Thybo Jensen, R., \& Thaning, M. S. (2017). McDowell's New Conceptualism and the Difference between Chickens, Colours and Cardinals. Philosophical Explorations, 20(1), 88-105. https://doi.org/10.1080/13869795.2016.1273377

Link to publication in CBS Research Portal

\section{General rights}

Copyright and moral rights for the publications made accessible in the public portal are retained by the authors and/or other copyright owners and it is a condition of accessing publications that users recognise and abide by the legal requirements associated with these rights.

\section{Take down policy}

If you believe that this document breaches copyright please contact us (research.lib@cbs.dk) providing details, and we will remove access to the work immediately and investigate your claim.

Download date: 26. Apr. 2023

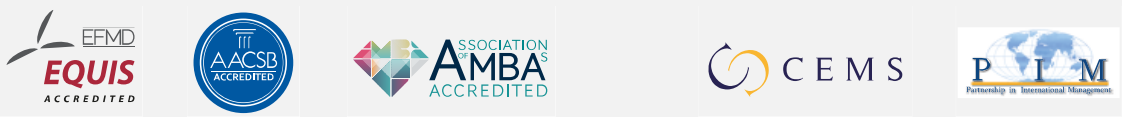




\section{McDowell's New Conceptualism and the Difference between Chickens, Colours and Cardinals}

\section{Johan Peter Gersel, Rasmus Thybo Jensen, and Morten Sorensen Thaning}

Journal article (Accepted manuscript*)

\section{Please cite this article as:}

Gersel, J. P., Thybo Jensen, R., \& Thaning, M. S. (2017). McDowell's New Conceptualism and the Difference between Chickens, Colours and Cardinals. Philosophical Explorations, 2a1), 88-105. D0l: 10.1080/13869795.2016.1273377

This is an Accepted Manuscript of an article published by Taylor \& Francis in Philosophical Explorations on 09 Jan 2017, available online:

http://www.tandfonline.com/10.1080/13869795.2016.1273377

* This version of the article has been accepted for publication and undergone full peer review but has not been through the copyediting, typesetting, pagination and proofreading process, which may lead to differences between this version and the publisher's final version AKA Version of Record.

Uploaded to CBS Research Portal: January २०19 


\title{
McDowell's new conceptualism and the difference between
}

\section{chickens, colours and cardinals}

\author{
Johan Gersel, Rasmus Thybo Jensen, Morten S. Thaning* \\ Independent researcher, Vienna, Austria; Independent researcher, Copenhagen, Denmark; \\ Copenhagen Business School, Department of Management, Politics and Philosophy \\ Forthcoming in Philosophical Explorations
}

\begin{abstract}
McDowell recently renounced the assumption that the content of any knowledgeable, perceptual judgement must be included in the content of the knowledge grounding experience. We argue that McDowell's introduction of a new category of non-inferential, perceptual knowledge is incompatible with the main line of argument in favour of conceptualism as presented in Mind and World (1996). We reconstruct the original line of argument and show that it rests on the assumption that a specific model of justification, the Comparison Model, must apply to all cases of non-inferential, perceptual knowledge. We then show that the Comparison Model cannot be applied to McDowell's new category of noninferential, perceptual knowledge. As a consequence, McDowell is in need of an alternative model of justification and an alternative argument for conceptualism. We propose such an alternative model of justification based on McDowell's reading of Sellars, but argue that the model only serves to make the need for an alternative motivation for conceptualism more urgent.
\end{abstract}

Keywords: McDowell; conceptual content; perceptual knowledge, recognitional skills, the Myth of the Given

\footnotetext{
*Emails: jgersel@gmail.com; rasmusthybo@yahoo.dk; mst.mpp@cbs.dk
} 
Draft version - please cite the official version

\section{Introduction}

A rational subject is one who can appreciate the adequacy of her grounds for judgements. What restrictions are placed on the nature of experience if we, as rational subjects, are to be able to appreciate such experiences as adequate grounds for non-inferential perceptual judgements expressive of knowledge? In Mind and World McDowell (1996) argued that we can only retain the idea that experiences can be recognized by subjects as such adequate grounds if we understand experiences as having conceptual content. This conditional is the basic claim of what we call 'McDowell's conceptualism'. In 'Avoiding the Myth of the Given' McDowell (2009c, 258) still defends this basic claim but renounces two assumptions that used to be a part of his conceptualism. The first assumption is the idea that in order for a subject to gain non-inferential knowledge on the basis of perception, the content of the knowledgeable judgement has to be included in the content of the knowledge grounding experience. Instead McDowell now argues that the content of a perceptually known judgement can outstrip the content of the perception which grounds that judgement. We will call the renounced view 'Unrestricted Conceptualism' and McDowell's new position on this issue 'Restricted Conceptualism'. The second change concerns how we should understand the claim that the content of experience is conceptual. McDowell used to think that the content of experience is given to the subject in a propositional form. He now thinks the content of experience, at least in so far as we are dealing with an object-directed experience, is given in what he calls an intuitional form that he contrasts with the propositional form of judgemental content. The content of experience is still conceptual in the sense that its availability involves our faculty of spontaneity; the same faculty that is involved in judgements. According to McDowell, this means that all aspects of the content of an intuition can figure seamlessly in the content of a judgement (McDowell 2009c, 264), and that is all that is required for it be characterized as conceptual content. We will call McDowell's old view on this issue 'Propositional Conceptualism' and his new view 'Intuitional Conceptualism'. 
Draft version - please cite the official version

Our main focus is McDowell's first change. We argue that this change leaves McDowell's conceptualism vulnerable to two challenges that he has thus far left unaddressed. McDowell's second change is logically independent of the first (cf. McDowell 2009c, 258). We only address the second change in order to settle whether our two challenges are affected by it.

Section 1.1. presents McDowell's first change. In section 1.2. we argue that McDowell's Mind and World argument for conceptualism rests on the assumption that a single model of justification, what we call 'the Comparison Model', must apply to all cases of non-inferential perceptual knowledge. Next (section 1.3.) we argue that McDowell's newly introduced category of non-inferential perceptual knowledge cannot be understood in accordance with the Comparison Model. The consequence of this is twofold: McDowell needs an alternative model of justification for the new category of non-inferential perceptual knowledge, and he is in need of an alternative motivation for his conceptualism. In the second part of the paper (section 2.1., 2.2. and 2.3.) we turn to McDowell's second change and argue that the adoption of Intuitional Conceptualism makes no substantial difference to the two challenges raised in the previous paragraph. In the third part of the paper (section 3.1. and 3.2.) we suggest that we can use McDowell's interpretation of Sellars in order to articulate at least the contours of an alternative model of perceptual justification, which we call 'the Authority Model'. We argue that it is congenial to McDowell's internalism about justification. Moreover, it enables one to account for the rational entitlement we are supposed to have in cases that belong to McDowell's new category of non-inferential, perceptual knowledge. In the last section (section 3.3.) we point out that there are no obvious reasons why the Authority Model could not completely replace the Comparison Model. This possibility of generalizing the Authority Model puts further pressure on McDowell to provide an alternative motivation for his conceptualism. 
Draft version - please cite the official version

\subsection{The difference between the old and the new view}

When explicating his new position, McDowell starts from the intuition that a properly skilled bird watcher can upon encountering a cardinal acquire non-inferential perceptual knowledge of the proposition 'that bird is a cardinal'. What bothers McDowell is that he has become convinced that the experience of such a skilled bird watcher could in all relevant respects be similar to the experience of another mature thinker, who is also looking at the cardinal, but who simply lacks the concept 'cardinal' (McDowell 2009c, 258-59). On McDowell's early view this would be impossible. Given that the skilled bird watcher can non-inferentially know that that bird is a cardinal on the basis of her experience, it follows from Unrestricted Conceptualism that this experience must include the concept 'cardinal' in its content. However, such content couldn't possibly form part of the content of the experience of the unskilled bird watcher standing next to her, since she, ex hypothesi, doesn't possess the required conceptual capacity. It is in order to accommodate both the intuition that the possession of certain concepts, like 'cardinal', is irrelevant to the determination of our experiential content, and the intuition that perceptual judgements involving such concepts can amount to noninferential knowledge, that McDowell lets go of his prior commitment. He now rejects the assumption that the content of a knowledgeable non-inferential perceptual judgement needs to be included in the content of the knowledge grounding experience. This is the change from Unrestricted Conceptualism to Restricted Conceptualism.

On McDowell's new view the epistemic advantage of the skilled bird watcher is not to be explained by the fact that she has a richer experiential content. Rather, the advantage is explained by reference to the possession of a recognitional capacity that she can bring to bear on the object given in perception. When seen under the right circumstances the visual presence of a cardinal simply gives rise to an inclination to judge that the bird is a cardinal, and if the circumstances are epistemically beneficial then the judgement, if made, will amount to non-inferential knowledge (McDowell 2009c, 259). ${ }^{1}$ 
Draft version - please cite the official version

The core difference between McDowell's old and new position is that the novel view accepts an important dichotomy within our recognitional concepts. On the one hand, there are the fundamental concepts. These must form part of the content of our experiences if such experiences are to provide knowledge-yielding reasons for non-inferential perceptual judgements including those concepts. On the other hand, there are the non-fundamental concepts. These need not form part of the content of our experiences if such experiences are to provide knowledge-yielding reasons for non-inferential perceptual judgements including those concepts. In what follows we will use 'fundamental judgement' to refer to judgements exclusively employing fundamental concepts and 'nonfundamental judgement' for judgements which include at least some non-fundamental concepts. McDowell does not provide a principled way of determining on which side of the divide any given concept falls, but states that it would be natural to draw the line by appealing to the notions of proper and common sensibles (McDowell 2009c, 260). In the case of vision this would mean that fundamental concepts would be those that refer to the proper and common sensibles accessible to vision, such as for example colour, shape and size (McDowell 2009c, 261). However, precisely where and how one draws the distinction between these two types of concepts is irrelevant to our arguments. The crucial assumption is that such a distinction between two types of concepts exists. For this reason, we prefer to use to the formal notions 'fundamental' and "non-fundamental' rather than McDowell's more substantial notions of proper and common sensible vs. non-sensible properties.

McDowell holds that non-fundamental perceptual judgements are psychologically non-inferential in the sense that no psychological process of inference has led the subject to form the judgement. He also claims that these 'cardinal'- judgements are epistemologically non-inferential. By this he means that a vindication of them as expressive of knowledge need not involve an appeal to inferences that include premises that can be known independently of the proposition in question (McDowell 2010b, 141; see also McDowell 1998b, 416). ${ }^{2}$ If McDowell accepted that perceptual non-fundamental 
Draft version - please cite the official version

knowledge was in fact a disguised case of inferential knowledge, then he could retain his Unrestricted Conceptualism. He would be able to argue that Unrestricted Conceptualism held for all truly non-inferential perceptual knowledge; all the while he argued that once inferential perceptual knowledge was considered the presence of the inferential link allowed for novel concepts, not present in the content of the experience, to enter into the content of our justified perceptual judgement. ${ }^{3}$ However, McDowell is adamant that our non-fundamental perceptual judgements are equally non-inferential (McDowell 2009c, 259).

\subsection{The Comparison Model of experiential justification in Mind and World}

When McDowell formulates his conceptualism in Mind and World he does not explicitly consider the possibility of the distinction between fundamental and non-fundamental concepts. Yet, our claim is that the way McDowell argues for conceptualism in Mind and World makes it incompatible with this distinction. The incompatibility arises from the model of justification that supports McDowell's conceptualism in Mind and World, and we will therefore begin by presenting this model.

The basic intuition running through both Mind and World and his revised position is what McDowell calls Minimal Empiricism, which claims that if we are to make sense of our thoughts as world directed at all, then our practice of thinking must be rationally constrained by the world itself through perception:

This is what I mean by "a minimal empiricism": the idea that experience must constitute a tribunal, mediating the way our thinking is answerable to how things are, as it must be if we are to make sense of it as thinking at all. (McDowell 1996:

xii)

Formulated as above Minimal Empiricism doesn't come with an explicit commitment to conceptualism; neither Unrestricted nor Restricted. It is an additional claim of McDowell's that unless we can regard perception as possessing conceptual content then the requirement of Minimal 
Draft version - please cite the official version

Empiricism cannot be fulfilled. Borrowing the terminology from Sellars, McDowell's claim is that unless we accept conceptualism we cannot conceive of experiences as figuring within 'the logical space of reasons', that is, within the web of rational relations that affect our thinking and judgements (cf. Sellars 1997, §36). However, Minimal Empiricism requires that experiences can figure as reasons for belief, hence, experiences must possess conceptual content. Yet, why accept that experiences can only figure in the logical space of reasons if they possess conceptual content? At this stage, we need a clearer idea of the conception of justification that McDowell works with in Mind and World.

The first aspect to highlight is the internalist nature of McDowell's conception of justification. McDowell urges that we must avoid a picture where we can only make sense of subjects as rational when we evaluate them from an external, third personal perspective. For instance, an account would fail to live up to the internalist requirement if it claimed that the only epistemic role of a sensory impression was as an intermediary in a reliable relation between a perceptual judgement and the fact which accounts for its truth. It might look like the mere existence of a sensibly mediated correlation between judgement and world could ensure the external constraint required by Minimal Empiricism. However, the mere existence of such a correlation fails to show how it could be rational from the subject's point of view to judge one way rather than another in the light of what is given to her in experience. It would be of no help to add that the subject might have justified beliefs about the existence of such a reliable correlation (McDowell 1996, 144-145). On such an account, what is supposed to justify the subject is the first personal availability of a good inference with the reliability assumption as one of its premises. Such an account could at best make our perceptual justification inferential.

McDowell elaborates his internalist requirement in terms of scrutinizability. In order for something to properly count as a reason from the subject's own point of view, it must be possible for the thinker herself to scrutinize the adequacy of the putative reason as a sufficient reason for whatever judgements she is inclined to make on its basis (McDowell 1996, 12, 34, 52). Thus, to 
Draft version - please cite the official version

McDowell the space of reasons inhabited by a subject cannot extend beyond the realm of what the subject can scrutinize for epistemic adequacy: "We cannot put limits on the self-scrutiny of reason" (McDowell 1996, 52). How does one scrutinize the epistemic adequacy of one's reasons? An obvious way in which this might be done is if one represents one's reasons in thought and evaluate whether they entail, or at least make likely, the truth of one's belief. In other words, one considers whether there is some form of valid inference that one can draw from one's reasons to the truth, or likelihood of truth, of one's judgement. In Mind and World, we find a conception of scrutinizability that exactly emphasizes the possibility of evaluating an at least potential inferential relation, also in the case of experiential reasons. This understanding of scrutinizability is made explicit when McDowell writes:

But we cannot really understand the relations in virtue of which a judgement is warranted except as relations within the space of concepts: relations such as implication and probabilification, which hold between potential exercises of conceptual capacities. (McDowell 1996, 7, see also 53)

Crucially, this understanding of scrutiny neither requires that knowledgeable judgements are psychologically nor epistemologically inferential. In order to be available for scrutiny a reason need not have served as the premise of an inference the subject actually made when she formed her judgement. Furthermore, in order for it to be possible for a subject to evaluate whether there is a good inference from one's reason to the truth of one's judgement, one's reason need not be available as knowledge independently of the knowledge which it figures as a reason for. McDowell argues that my reason for believing that there is a red cube in front of me can be that I see that there is red cube in front of me (McDowell 2006b, 134). Such a reason is factive in the sense that it entails the truth of the judgement to which it entitles the subject. If my knowledge is based on such an experiential, factive reason then my reason is not something that can be known independently of knowledge of the proposition it figure as a reason for. If a rational subject knows that she sees a red cube in front of her, eo ipso she knows that there is a red cube in front of her. ${ }^{4}$ 
Draft version - please cite the official version

McDowell argues that this idea of scrutinizability through representation in thought requires the represented, putatively reason-constituting items to be bearers, not only of representational content, but also of conceptual content. That these requirements are logically separable is apparent when one contrasts McDowell's conception with certain forms of non-conceptualism. Like McDowell, non-conceptualists regard experiences as having representational content and so as possessing truth- or, as some favour, veridicality-conditions. This means that there can be straight-forward relations of implications between veridical experiences and the truth of judgements. The state of the world required for an experience to be veridical can be such that the veridicality of such an experience implies the truth of a given judgement. My experience and my judgement may both require that the grass is green for the first to be veridical and the second to be true. Thus, the problem for the non-conceptual representational theory of experience isn't that experiences cannot properly entail or make likely the truth of judgements. The problem, according to McDowell, is rather that the subject undergoing the experience is unable to evaluate from a first-person perspective whether the non-conceptual content of a given experience is suitably related to the conceptual content of the judgement it is supposed to justify. McDowell puts forward his argument in the following critique of Peacocke:

It does not follow that something whose content is given by the fact that it has the correctness condition that P can eo ipso be someone's reason for, say judging that $Q$, independently of whether the content is conceptual or not. We can bring into view the rational relations between the contents - it's being the case that $P$ and its being the case that $\mathrm{Q}$ - only by comprehending the putatively grounding content in conceptual terms, even if our theory is that the item that has the content does not do its representing in a conceptual way. A theory like Peacocke's does not credit ordinary subjects with this comprehensive view of the two contents, and I think that leaves it unintelligible how an item with the non- 
Draft version - please cite the official version

conceptual content that $P$ can be someone's reasons for judging that $Q$. (McDowell 1996, 166)

One reason why Peacocke's theory doesn't credit ordinary subjects with the needed comprehensive view of the content of both the justifying experience and the content of the justified judgement is that an ordinary subject doesn't possess the required vocabulary, i.e. the theoretical vocabulary developed by Peacocke, needed to articulate the non-conceptual content of experience. But even if we supposed that we all were in possession of such a theory it would still not, according to McDowell, be enough for us to hold on to Minimal Empiricism (McDowell 1996, 165). We would be in a position that makes our perceptual knowledge at most psychologically non-inferential. On McDowell's lights it would neither be of help to suppose the existence of some reliable function which allows us to conceptualize the non-conceptual content of experience and, thereby, acquire a conceptually structured representation with equivalent truth-conditions to those possessed by the non-conceptual content. ${ }^{5}$ We would still not be able to make sense of the basic idea of Minimal Empiricism, i.e. the idea that sometimes it is the world itself that sets the norm for what I should judge through its manifestation in experience. On the view in question it would never be the world itself that functions as an external constraint on my judgements in a way that I can access and rationally evaluate. What I can access and rationally evaluate would always be one step removed from the impression made by the world upon me, since that impression possesses only nonconceptual content and any evaluation of a putative reason-constituting relation requires the content of the items involved to be articulated conceptually. On McDowell's view there is no need for any such transformation function, since the very same conceptual capacities that can be exercised in judgement are already passively actualized in experience. The subject will, simply by having the experience, have immediate access to the content of the experience in a conceptual form. This access allows the subject to compare the very content of the experience with the content of the judgement which is supposed to be justified by the experience and, thus, allows her to evaluate 
Draft version - please cite the official version

whether there is a good inference from the content of the former to the content of the latter. Since the possibility of scrutiny according to this model is based on the possible comparison of the content of experience with the content of one's judgement, we will call this 'the Comparison Model' of epistemic justification and scrutiny.

If our reconstruction of the basic line of argument in favour of conceptualism found in Mind and World is correct then it relies on the following idea: Only if there exists an inferential relation appreciable from the subject's point of view between the content of an experience and the content of a judgement can we make sense of the idea that experience directly reveals the world to the subject in a manner that allows for non-inferential perceptual knowledge. In other words, the argument in Mind and World depends on the generality of the Comparison Model of scrutinizability when it comes to non-inferential perceptual knowledge. The argument can only establish the conclusion that we must regard experience as possessing conceptual content in order to hold on to Minimal Empiricism, if it is assumed that any case of non-inferential perceptual knowledge must live up to the requirement of scrutinizability as it is understood on the Comparison Model. Without this assumption, it would remain an open question whether an alternative model of scrutiny could secure the kind of non-inferential, experiential justification needed for us to hold on to Minimal Empiricism; an alternative model whose applicability might not imply that experience has conceptual content. It is therefore a pressing question whether the non-inferential, non-fundamental perceptual knowledge that we can have according to McDowell's new position can be accounted for by the Comparison Model.

\subsection{The inadequacy of the Comparison Model}

As we shall see, the epistemic dichotomy between fundamental and non-fundamental perceptual judgements bars one from using the Comparison Model as a general model for all non-inferential perceptual justification. The problem is that, given Restricted Conceptualism, there is in the case of 
Draft version - please cite the official version

non-fundamental judgements no guarantee that a valid inference can be made from the conceptual content of the grounding experience to the content of the non-inferentially justified judgement. One cannot display the rationality of a non-inferential judgement that that bird is a cardinal simply by appealing to the content of the experience on which it is based. The content of the grounding experience might be along the lines of 'that object is an animal' or 'that bird is red'. Yet, as there are many red birds and animals that aren't cardinals there is no valid inference from the former premises to the conclusion that that bird is a cardinal. It won't help to expand the supposed content of the experience such that its content is along the lines of 'that animal is a bird with a distinctive shape A and colour B at my current location'. Even if I am presently in North-America and the only birds with shape A and colour B located here are cardinals, this won't help explain the adequacy of my experience as a sufficient reason for my judgement that the bird is a cardinal. For general facts about the bird population in North-America are surely not parts of my experiential content. The only way such facts could enter into my justification would be as premises in an inference that takes me from independently known facts to the conclusion that what is before me is a cardinal. However, this would make the original judgement at most psychologically non-inferential, yet epistemically inferential. We can conclude that it would simply be incoherent to exclusively operate with the Comparison Model and at the same time insist on the possibility of genuinely non-inferential perceptual knowledge that extends beyond the content of the grounding experience. In short, McDowell's new position cannot employ the Comparison Model of scrutiny in relation to nonfundamental perceptual judgements. ${ }^{6}$

We can now formulate a twofold challenge that McDowell faces. First, he needs an alternative model of scrutiny that will allow us see how a subject can be entitled to non-fundamental perceptual judgements even though there is no valid inference from the content of the grounding experiences to the content of the grounded judgements. Given how central the idea of rational scrutiny is to McDowell's overall conception of justification the absence of such an alternative model would be a 
Draft version - please cite the official version

serious lacuna. Secondly, not only must this alternative model be coherent with ascribing some conceptual content to experience, McDowell is also in need of a new argument as to why Minimal Empiricism requires us to ascribe any conceptual content to experience. For upon endorsing Restricted Conceptualism, McDowell can no longer defend the need for any type of conceptualism through his earlier argumentation, as that argument relied on the generality of the Comparison Model.

\subsection{Intuitional Conceptualism and the Comparison Model $^{7}$}

Thus far we have only considered the first of the two changes McDowell has made to his theory of experience; the change from Unrestricted to Restricted Conceptualism. We have taken the liberty of speaking of the restricted conceptual contents of experience as if they were propositionally structured. However, McDowell no longer considers experiential content to be propositionally structured even if he still claims that it is conceptually structured. McDowell's change from Propositional Conceptualism to Intuitional Conceptualism means that there is an even simpler argument as to why the Comparison Model cannot be maintained. According to the Comparison Model adequate perceptual justification requires two things: a valid inferential relation between the content of one's judgement and the content of one's experience; and the content of one's experience must be fully conceptual in respect of the knowledgeable judgement. McDowell's second change is clearly incompatible with the first requirement. Inferential relations only exist between propositions. If experiential content isn't propositional then it cannot figure in inferential relations. In fact, McDowell readily acknowledges that his new view rules out such inferential relations (McDowell 2009c, 270-271).

It is, however, quite important to realize that the two challenges we have presented have their root in McDowell's endorsement of Restricted Conceptualism; not his endorsement of Intuitional Conceptualism. In what follows we first argue that Intuitional Conceptualism as such does not 
Draft version - please cite the official version

undermine the basic motivation for McDowell's conceptualism; we then argue that when combined with Restricted Conceptualism it is nevertheless bound to give rise to the two challenges spelled out above.

\subsection{Intuitional Conceptualism and the Mind and World argument}

The reason why McDowell's change to Restricted Conceptualism does not pose an immediate threat to his overall defence of conceptualism, is that the conflict between the Comparison Model and Intuitional Conceptualism may be overcome by appealing to the spirit rather than the letter of the Mind and World argument. With his new view, McDowell stays just as committed to internalism concerning justification as before (McDowelll 2009c, 256). On the old view, what makes it intelligible that the subject is in a position to appreciate the reason-constituting relation between her experience and her judgment is partly the fact that there is an inferential relation between the content of the experience and the content of the knowledgeable judgement. On the new view, we cannot, as McDowell puts it, "connect the experience's content so directly with what it enables its subject to know". The connection is however, McDowell urges, "still obvious" (McDowell 2013, 145):

if an experience presents someone with an object as red and rectangular and in front of her, it enables her to know there is something red and rectangular in front of her. (McDowell 2013, 145; see also McDowell 2009c, 271)

The basic idea is still that one is entitled to one's judgement by being presented directly with reality itself, only now not in the form of facts but in the form of an object that is "present to one through the presence to one of some of its properties" (McDowell 2009c, 271). When things go well one sees the red object as for instance red. But not only that: one's seeing it as red is simply one's being presented with the object's actual colour, something which guarantees the truth of a judgment that claims that the object is red (McDowell 2013, 152; McDowell 2011, 31). What McDowell introduces with Intuitional Conceptualism is a new species of the genus rational relation; the kind of "relations 
Draft version - please cite the official version

in virtue of which a judgement is warranted" (McDowell 1996, 7). The new kind of rational relation is still a truth-ensuring relation just like the inferential relation, and it is supposed to be recognizable as a rational relation at least partly in virtue of the content of the experience. Both on McDowell's old and new view there are two central demands that experiences must live up to if they are to play the part required by Minimal Empiricism: ${ }^{8}$ (A) Experiences must stand in what we might call an alethic relation to the knowledgeable judgements that they provide warrant for; (B) the fact that they stand in such an alethic relation must be accessible to the subject. By an alethic relation, we mean a truthensuring relation where what provides reasons for one's judgements ensures its truth. ${ }^{9}$ McDowell initially assumed that the relevant alethic relation had to be the relation of inferential validity. However, as displayed in McDowell's critique of Peacocke's non-conceptualism, it was never the need for an inferential link as such that drove McDowell's argument in favour of conceptualism (cf. section 1.2.). Rather, the key premise was the need for the subject to have access to and thereby be in position to evaluate whatever putative rational link there may be.

In Mind and World, the inferential link between the two contents was taken to be a necessary condition for a rational link between experience and judgement, because it was assumed that only such an inferential relation would make the possibility of scrutiny intelligible; an assumption shared by the non-conceptualist. Renouncing this assumption leaves room for a parallel argument in favour of conceptualism that respects the idea that what we are presented with in experience is objects not facts. The basic idea would still be that we need to regard the content of experience as involving conceptual capacities in order for the subject's reflective self-consciousness of her experience not to involve an intermediary step of conceptualization of a non-conceptual given. On his new view, McDowell expresses the content of such a reflective self-consciousness as follows: "I'm visually confronted with an object with such-and-such features" (McDowell 2009c, 266; see also McDowell $2013,151)$. The new version of the old argument would claim that such a visual confrontation with an object, i.e. a seeing of an object with some of its features, itself needs to involve conceptual 
Draft version - please cite the official version

capacities if we are not to insert a distance between that which is given in experience and that in light of which a subject is able to reflectively scrutinize the propriety of her judgement. This argument would still appeal to a minimal and general version of the Comparison Model for scrutiny. It would still be assumed that in order for a subject to be rationally entitled to non-inferential perceptual judgements the subject must be able to reflectively acknowledge that how an object is represented as being in her experience matches how her judgement states them to be.

\subsection{Intuitional Conceptualism and the two challenges}

Importantly an appeal to such an argument would only overcome the obstacle introduced by McDowell's second alteration. Intuitional Conceptualism might work, but as soon as Restricted Conceptualism enters the scene our two challenges follow.

It may seem that the prospects for a uniform account of justification that covers both fundamental and non-fundamental judgements are better, given the new, more liberal conception of how experience can provide truth-ensuring warrant. ${ }^{10}$ After all, what made the non-fundamental judgement unamenable to the Comparison Model was exactly the absence of such an inferential link (cf. section 1.3.). However, the hope for such a uniform account dissolves once we consider how, on the new model, the rational relation between experience and fundamental judgements still depends on the content ascribed to the experience because of McDowell's continuous commitment to the demand for accessibility specified in (B) above. To see this, let us begin with a clarification of how McDowell's Restricted Conceptualism lives up to the requirement of an alethic link specified in (A) above.

Consider an experience of a cardinal. According to McDowell's Woodbridge Lectures, intuitional content is object-dependent in the same sense that Evan's argued that the content of a demonstrative judgement ("That object is red and rectangular") based on experience is objectdependent (McDowell 2009a, 49). Such a view immediately implies a strong relational view of 
Draft version - please cite the official version

experience, i.e. a view according to which a given experience of an object could not be the experience it is without the existence of the particular object experienced. This means that undergoing this particular type of experience, of a specific cardinal, metaphysically ensures the truth of the judgement that that bird is a cardinal. Importantly, it can do so independently of whether the concept 'cardinal' is part of the conceptual content of the experience. As long as the experience is individuated in terms of its referents, properties beyond those represented in the experience can be metaphysically determined by the occurrence of the experience. ${ }^{11}$

Assuming there are such alethic relations between experiences and the appropriate nonfundamental judgements, this still doesn't tell us anything about how the presence of such relations could be accessible to the subject undergoing the experiences. ${ }^{12}$ In the case of fundamental judgements, the relation is accessible because the subject is conscious of both how the world is presented as being, i.e. the intuitional content of the experience, and of the genuinely worldrevealing character of the experience (McDowell 2009c, 267). But in the case of non-fundamental judgements it is exactly ruled out that the judgements could articulate a way the world is revealed to be through the content of intuitions, since the properties of objects known in such judgement are of a kind that in principle could not be presented intuitionally.

We can conclude that the prospects of transferring the model for justification that McDowell takes to be appropriate for fundamental judgements to non-fundamental judgement is in no way improved by combining Restricted Conceptualism with Intuitional Conceptualism. Consequently, McDowell is still faced with the first challenge articulated above. He is still in need of an alternative model of justification for his new category of non-inferential perceptual knowledge.

What about the second challenge; i.e. that McDowell needs a new argument in favour of conceptualism? Just like the original version, the modified Mind and World argument rests on the assumption that non-inferential perceptual knowledge requires that the subject is in a position to compare the content of her judgement with the content of her experience and thereby come to 
Draft version - please cite the official version

reflectively appreciate the alethic relation between them. But this is exactly the assumption we have just seen is incompatible with adopting Restricted Conceptualism. Hence the second challenge also stands.

\subsection{The Authority Model of experiential justification}

It is now apparent that Restricted Conceptualism introduces a problem common to both the original line of argument in favour of conceptualism and the novel variant which takes into account McDowell's change to intuitional content. The central problem is that both lines of argument rely on conceiving of non-fundamental perceptual knowledge as being available for scrutiny in a way that is analogous to how we scrutinize the adequacy of our reasons for fundamental perceptual judgements. Both arguments assume that all forms of non-inferential perceptual knowledge rely on the availability of some form of comparison between what is given in the experience and the content of the judgement made. However, the possibility for scrutinizability in the non-fundamental case cannot help but seem completely independent of the conceptual nature of the content of the knowledge grounding experience. It seems so because the proposed rational relation cannot be made explicit in terms of how things are perceptually represented in the experience itself, conceptually or not. In the case of non-fundamental perceptual knowledge, the relevant truthensuring relation isn't constituted specifically by how things are represented in the experience. It rather relies on the non-represented metaphysical nature of what is represented. But if our scrutiny of rational relations can in this way exploit relations going beyond how things are represented in experience, it is difficult to see how the general requirement for scrutiny could entail restrictions on how things must be represented as being. If the possibility of scrutiny isn't as such restricted by how things are represented as being more generally, why should it require that the way things are represented is specifically conceptual? Phrased like this the next step in the debate is easily discernible. McDowell might respond precisely by denying that the methods of scrutiny and the 
Draft version - please cite the official version

forms of justification are analogous in the fundamental and non-fundamental case. Both count as cases of non-inferential perceptual knowledge, but their underlying epistemic structures differ.

In 'Avoiding the Myth of the Given' McDowell does in fact indicate that he takes non-fundamental judgements to be justified in a different way than fundamental judgements. He says that in the fundamental case it is the experience itself which entitles us, whereas in the non-fundamental case the experience merely "figures in our entitlement to judgement" (McDowell 2009c, 279-80). ${ }^{13}$ We will argue that in McDowell's interpretation of Sellars' Empiricism and the Philosophy of Mind, we find the articulation of a view of rational scrutiny that would allow McDowell to answer the first challenge which was to explain how we can scrutinize the epistemic adequacy of non-fundamental perceptual judgements. We take the feasibility of the proposed model to be independent of whether Restricted Conceptualism is combined with Intuitional or Propositional Conceptualism.

McDowell attributes to Sellars the idea that one can approach the question of one's justification for a perceptual judgement in two separate ways. ${ }^{14}$ On the first way, one directly considers whether one's reasons tell in favour of the truth of one's judgement (McDowell 2009b, 224). On this approach, one indeed needs assurance that one's reasons in some way ensures or make likely the truth of one's judgement. As we have seen McDowell's approach to our scrutiny of experiential justification in Mind and World was of this form. About the second approach McDowell writes: "What one addresses, in the first instance, is not the truth of the particular thing the person says, but her authority, in the circumstances, to say something - anything - of the relevant sort" (McDowell $2009 \mathrm{~b}, 234)$. This account of what entitles one to make a certain claim is thus concerned with whether the conditions are such that the subject is allowed to count herself as a knower. Since the focus of scrutiny in the latter model is on the authority of the subject to say or think "anything of the relevant sort", we call this 'the Authority Model' of epistemic justification and scrutiny.

To illustrate the difference, imagine one enquires into the epistemic adequacy of a perceptual judgement about the colour of something seen. To justify one's judgement that the tie is green in 
Draft version - please cite the official version

accordance with the Comparison Model one would cite such reasons as: I see that the tie is green. The scrutiny of the putative reason would proceed through an evaluation of the inferential or at least truth-ensuring relations between the content of one's experience and the content of the judgement. The attempt is to establish whether the truth of the judgement follows from the veridicality of the experience. A justification according to the Authority Model might begin with the same sentence 'I see that the tie is green', but once the subject begins an evaluation of the epistemic adequacy of her perceptual judgement she would cite reasons such as: The lighting conditions are good for seeing colours and I know colours when I see them under good conditions. As McDowell suggests: "I might say: 'I can tell a green thing when I see one (at least in this kind of light)'” (McDowell 2009b, 232). Whereas the former model of justification and scrutiny is thus directly concerned with whether the subject's judgement that the tie is green is true, the latter line of justification primarily tries to establish the subject as a knower regarding colours. Of course, from there one can quickly provide an inferential line of argument to the truth of the subject's judgement, because knowers form true judgements. However, it's important that this inferential line of argument establishing the truth of the subject's judgement is not an inherent part of the subject's establishment of her epistemic authority (McDowell 2009b, 234).

\subsection{The role of background knowledge in the Authority Model}

Justification according to the Authority Model requires that one possesses a capacity for reliable differential responsiveness to features of the environment and that one has knowledge of this general reliability. Furthermore, it requires that one has knowledge of the specific situations which can figure as support or defeaters in the evaluation of one's right to rely on this differential responsiveness in making a judgement (McDowell 2009b, 223). Without these elements, the Authority Model would regress to the myth of the Given which assumes that a bare sensory given can provide justification on its own. In contrast, on the Authority Model a justified subject must be 
Draft version - please cite the official version

able to cite his own possession of the recognitional skill and the absence of defeaters as grounds for his epistemic authority. This might seem to imply that on the Authority Model what gives one's perceptual judgement their authority as expressions of knowledge is really an inference: Since I know that under normal circumstances I have a reliable differential disposition to apply colour concepts correctly and since I know that circumstances are normal in the present situation, then if I now have the inclination to judge that the colour of the tie in front of me is green, then I also have the right to claim that it is green. It is crucial that we can avoid such an understanding of the Authority Model if it is to account for our ability to scrutinize non-inferential, non-fundamental, perceptual judgements.

The way out of this predicament is to notice two different roles that background knowledge can play in our acquisition of empirical knowledge on the basis of perceptions. According to the first inferential role, possession of certain background knowledge provides us with further premises that allow us to draw conclusions about something which cannot be justified on the basis of our perception alone. The background knowledge thus figures as an epistemically necessary premise in our reasoning. We may be so used to employing that premise and engaging in the inference that we skip the stage of psychologically inferring, yet this removes none of its epistemic importance. An illustrative example is the case of the expert chicken-sexers. It is assumed that such chicken-sexers can reliably separate male from female chicks even though they have no conscious awareness in any sensory modality of the features of their environment they are responsive to (McDowell 2010a, 14042). If a chicken-sexer is in possession of knowledge about the reliability of her inclinations to judge one way rather than another, she will be able to infer that there is a good chance the chick she is looking at is a male from the fact that she is inclined to judge that it is male. Such judgement would be internally justified but crucially the justification can at most be psychologically non-inferential.

According to the second non-inferential role, possession of certain background knowledge is partly constitutive of our possession of epistemically self-sufficient capacities. Such capacities for knowledge are self-sufficient in the sense that their successful exercise yields knowledge that the 
Draft version - please cite the official version

subject is able to vindicate as knowledge without appealing to an inference in which the background knowledge serves as premises. Already in Mind and World, McDowell argued that unless a subject possesses a certain amount of proper background knowledge we cannot conceive of that subject as seeing anything at all, in the sense of seeing that matters for Minimal Empiricism (McDowell 1996, 31). Colours are only sensibly present to me in experience due to my possession of some background knowledge regarding how lighting conditions affect colour appearances and so forth. Without such knowledge, I wouldn't count as having colours given to me in experience at all. ${ }^{15}$ Crucially, when background knowledge plays this constitutive role the epistemic ground for our judgements is quite different from that of the chicken-sexer. Someone who possesses the required background knowledge for seeing colours can have the green colour of a tie immediately given to her in vision by virtue of the passive actualization of her concept of green in sensory consciousness. However, seeing that something is green is in itself sufficient support for the conclusion that it is green. Hence, the background knowledge that enabled such vision need not enter one's justification in the form of a premise.

This is McDowell's earlier story and, while it will still work for fundamental, perceptual judgements, it is inadequate as an account of non-fundamental perceptual knowledge. Given McDowell's commitment to Restricted Conceptualism he can no longer insist that non-inferential perceptual knowledge requires the facts known to be themselves revealed through the content present in sensory consciousness. The pressing question is how such non-fundamental perceptual knowledge can be accounted for without assimilating the cardinal recognizer to the chicken-sexer. We can avoid such assimilation if we can apply the idea that background knowledge plays a constitutive rather than an inferential role in non-fundamental perceptual judgements.

In 'Avoiding the Myth of the Given' McDowell' indicates that locutions such as "I see that..." and "My experience reveals to me that..." can be used to express what entitles one to a piece of noninferential knowledge even in cases where the proposition in the "that..." clause is one that contains 
Draft version - please cite the official version

non-fundamental concepts (McDowell 2009c, 259). In the case of for instance the bird watcher such a usage cannot serve to "classify her noninferential knowledge, as knowledge she has by virtue of the visual presence to her of the state of affairs she knows to obtain" (McDowell 2010a, 142), since, ex hypothesi, the fact that the bird is a cardinal is not sensibly present. However, we can take the use of such locutions to be a way of classifying her non-inferential knowledge as knowledge she has by virtue of her visual recognitional capacity. The reliable differential responsive disposition of the bird watcher can be regarded as of a kind that depends for its possession on background knowledge, such as knowledge about the reliability of her ability to tell a cardinal when she sees one and about which circumstances should make her resist her inclination to judge that a perceived bird is a cardinal. ${ }^{16}$ This contrasts with the disposition to judge of the chicken-sexer which she would possess even in the absence of any knowledge of her own reliability and the circumstances that reliability requires. Even if 'cardinal' is not part of the content of the experience there is still a decisive parallel between the case of judgements involving concepts such as 'cardinal' and the case of judgements involving colour concepts where it is the experience itself that puts the subject in a position to know. In both cases background knowledge enables a subject to be in an epistemically self-sufficient position, and in both cases this self-sufficiency is partly due to the constitutive connection between the capacity to be in the relevant state of seeing or recognizing and the possession of certain background knowledge. In contrast the chicken-sexer's disposition to judge the sex of chickens lacks such a constitutive connection with any background knowledge. The disposition therefore only becomes epistemically significant through the addition of independent background knowledge, thus making any knowledge based on the inclination to judge one way rather than another inferential knowledge.

It is important to recognize how our proposal makes the usage of locutions such as "I see that..." available as a way of expressing one's non-inferential entitlement in the cases of non-fundamental recognitional concepts. Here it is not the possibility of a comparison of the content of the experience with the content of the justified judgement that would allow the subject to recognize an inferential 
Draft version - please cite the official version

or at least truth-ensuring relation between them. Such a possibility is precisely what is absent. Rather, it is the fact that the subject can scrutinize her rights to make judgements of the relevant kind according to the Authority Model. Such a scrutiny is always available in cases where the "I see that..." expresses a genuine entitlement to a non-fundamental perceptual judgement, since in such cases the locution is expressive of the passive workings of a rational recognitional capacity the possession of which constitutively requires relevant background knowledge. ${ }^{17}$

\subsection{The Authority Model and the motivation for conceptualism}

In the light of our appeal to the Authority Model above we can formulate a more specific version of the second challenge we raised by the end of section 1.3: If we can account for the non-inferential entitlement of the non-fundamental perceptual judgement by appealing to the Authority Model, what is then to hinder us from generalizing this appeal and use the Authority Model to give a complete account of our entitlement in the cases of fundamental perceptual judgements too? In the case of non-fundamental perceptual judgements the Authority Model allows us to see how such judgements can be justified without the fact known being revealed to the subject through the conceptual content of the experience. Thus, it seems that the prospect of generalizing the model to all cases of non-inferential perceptual knowledge could threaten the idea that experiences need to possess conceptual content at all.

It should be obvious that the Authority Model at least also applies to cases of fundamental perceptual knowledge. After all it is with references to such cases that McDowell introduces the model (McDowell 2009b, 234). The question is whether an appeal to the Authority Model on its own is sufficient for us to see that in such cases our judgements are rationally constrained by how things are. It might very well be true that we cannot make sense of our thoughts being about the empirical world if not at least some features of seen objects impinge on our sensory consciousness. However, the sensory presence of for instance the red colour of a seen cardinal might be considered necessary 
Draft version - please cite the official version

for us to be able to perceptually recognize the colour of the bird without this implying that it needs to be present in a conceptual form. We might think of our capacity to recognize a colour as red as on par with our capacity to recognize a bird as a cardinal. Possession of both capacities is constituted by some necessary background knowledge, and in neither case does our epistemic authority to make perceptual judgements depend inferentially on this background knowledge. In both cases, our recognitional capacity is so to speak put into operation by the visual presence of an object, with the only difference being that in the case of colour the feature recognized is in fact itself present in sensory consciousness. In both cases, it is the background knowledge that allows our judgement to be scrutinized for its rationality in accordance with the Authority Model, and in both cases the presence of such knowledge is necessary for the availability of conclusive reasons that can be articulated with "I see that..." locutions. However, if we accept all this there now seems to be no more reason to think that the fact that is non-inferentially known in the case of fundamental perceptual judgement must be given in the experience in a conceptual form, than there is to think that such should be the case in the case of the non-fundamental perceptual judgements. ${ }^{18}$

On the generalized version of the Authority Model it is never the experience alone that justifies one's perceptual judgements, since the experience is of a kind that could be had without the possession of the relevant recognitional capacities and possibly even without the possession of any conceptual capacities. However, the idea that experience must mediate "the way our thinking is answerable to how things are" (McDowell 1996, xii) doesn't imply that the mediation must be done by experience on its own. We must still avoid that the inclusion of elements beyond the experience in our account of perceptual justification implies that such justification becomes inferential. But the Authority Model is exactly supposed to show that our perceptual justification is non-inferential, and there seems to be no reason to think that the idea of passive actualization of recognitional capacities should give us less 'external control' on our thinking (McDowell 1996, p. 11) than what is provided by the idea of a passive actualization of conceptual capacities in sensory consciousness. 
Draft version - please cite the official version

McDowell argues that conceptualism is the only way to hold on to Minimal Empiricism while avoiding the Myth of the Given. Can the generalized Authority Model avoid the Myth of the Given? In Mind and World McDowell discusses two ways that one can fall into the Myth of the Given. The first is if one claims that a sensory impression devoid of any representational content can, on its own and independently of any background knowledge, justify our perceptual judgements (McDowell 1996, Lecture I). It should be obvious that the generalized version of the Authority Model doesn't fall into this category. On the generalized Authority Model the experience on its own cannot be said to justify perceptual judgements. Rather it is only in the context of a conceptual apparatus that includes perceptual, recognitional concepts with their accompanying background knowledge that we can come to regard perceptual appearances as an awareness "or at least a seeming awareness, of a reality independent of experience" (McDowell 1996, p. 31).

The second way of falling into the Myth of the Given discussed in Mind and World is if one takes experience to justify by virtue of its non-conceptual content. McDowell's argument against this view was that it is unable to live up the requirements of scrutinizability as conceived on the Comparison Model. However, since the generalized Authority Model is exactly providing an alternative to the Comparison Model it is not susceptible to this charge. The generalized Authority Model exactly challenges the idea shared by the non-conceptualist and Unrestricted Conceptualism that experiential justification depends on an inferential or at least truth-ensuring relation between the content of the experience and the content of the justified judgement.

In 'Avoiding the Myth of the Given' McDowell states that we fall into the Myth of the Given if we deny that "the rational faculty that distinguishes us from non-rational animals must also be operative in our perceptually being given things to know" (McDowell 2009c, 257). This is a version of the Myth of the Given because it claims that we can make sense of the idea that a subject has something given for knowledge, without "needing to have capacities that would be necessary for one to be able to get to know it" (McDowell 2009c, 256). However, no such claim is made on the generalized Authority 
Draft version - please cite the official version

Model. ${ }^{19}$ The claim is that just like in the case of seeing that a bird is cardinal, what in general makes it intelligible that the subject is in position to non-inferentially know things on the basis of perception is a combination of two facts: The sensory presence of the object and its features on the one hand, and the subject's recognitional capacities that are passively drawn into operation by this sensory presence on the other hand.

McDowell writes:

In giving one things to know, experience must draw on conceptual capacities. Some concepts that figure in knowledge afforded by an experience can be excluded from the content of the experience itself, in the way I have illustrated with the concept of a cardinal, but not all can. (McDowell 2009c, 260)

Given what we have said above it is not obvious why "not all can".

\section{Acknowledgements}

Johan Gersel's work on this paper was partly funded by a postdoctoral fellowship from the Danish Council for Independent Research, Humanities (No. 1030801001). Rasmus Thybo Jensen's work was partly funded by a postdoctoral fellowship from Japan Association for the Promotion of Science (JSPS) and the JSPS KAKENHI 2604747. The authors would like to thank Hagit Benbaji for her helpful comments on a prior version of this paper. 
Draft version - please cite the official version

\section{Notes on contributors}

Johan Gersel received his Ph.D. from University of Copenhagen in 2011 and has held a postdoctoral fellowship at the University of Copenhagen (Department of Media, Cognition and Communication).

Rasmus Thybo Jensen received his Ph.D. in $\mathbf{2 0 0 8}$ also from the University of Copenhagen and has held postdoctoral fellowships at University College Dublin (School of Philosophy), the University of Copenhagen (Department of Media, Cognition and Communication ) and at the University of Tokyo (Department of History and Philosophy of Science).

Morten S. Thaning is an associate professor at Copenhagen Business School (Department of Management, Politics and Philosophy) and received his Ph.D from the University of Aarhus in 2009.

\section{References}

Burge, Tyler. 2010. Origins of Objectivity. Oxford: Oxford University Press.

Crane, Tim. 2013. "The Given". In Mind, Reason and Being-in-the-World: the McDowell-Dreyfus Debate, edited by Joseph Schear, 229-249. London: Routledge.

Evans, Gareth. 1982. Varieties of Reference. Oxford: Oxford University Press.

Gersel, Johan. Forthcoming. "What is the Myth of the Given?". In In the Light of Experience: Essays on Reasons and Perception edited by Johan Gersel, Rasmus Thybo Jensen, Morten S. Thaning and Søren Overgaard. Oxford: Oxford University Press.

Heck, Richard G. 2000. 'Non-Conceptual Content and the "Space of Reasons"'. Philosophical Review 109 (4): 483-523.

McDowell, John. 1998a. "Criteria, defeasibility, and Knowledge". In Meaning, Knowledge, and Reality, 369-394. Cambridge, MA: Harvard University Press.

McDowell, John. 1998b. "Knowledge by Hearsay". In Meaning, Knowledge, and Reality, 414-443. Cambridge, MA: Harvard University Press. 
Draft version - please cite the official version

McDowell, John. 1996. Mind and World. 2. ed. Cambridge (Mass.): Harvard University Press.

McDowell, John. 2002. "Responses, Robert Brandom". In Reading McDowell - On Mind and World, edited by Nicholas H. Smith, 279-281. Routledge: London and New York.

McDowell, John. 2006a. "Response to Costas Pagondiotis". Teorema: International Journal of Philosophy, 25 (1):115-120.

McDowell, John. 2006b. "Response to Jonathan Dancy". In McDowell and His Critics, edited by Cynthia Macdonald and Graham Macdonald, 134-141. Blackwell Publishing.

McDowell, John. 2009a: "Intentionality as a relation". In Having the World in View - Essays on Kant, Hegel and Sellars, 44-55. Cambridge (Mass.): Harvard University Press.

McDowell, John. 2009b: 'Why is Sellars's Essay Called "Empiricism and the Philosophy of Mind?"'. In Having the World in View - Essays on Kant, Hegel and Sellars. 221-238. Cambridge (Mass.): Harvard University Press.

McDowell, John. 2009c. "Avoiding the Myth". In Having the world in view - essays on Kant, Hegel and Sellars, 256-272. Cambridge (Mass.): Harvard University Press.

McDowell, John 2010a. "Brandom on observation". In Reading Brandom, edited by Bernhard Weiss and Jeremy Wanderer, 129-144. New York: Routledge.

McDowell. John 2011. Perception as a Capacity for Knowledge. Marquette University Press.

McDowell, John 2013. "Perceptual Experience: Both Relational and Contentful”. European Journal of Philosophy, 21 (1): 144-157.

Millar, Alan 2007. "What the Disjunctivist is Right About". Philosophy and Phenomenological Research, 74 (1): 176-199.

O’Shea, James, R. 2010. “Having a Sensible World in View: McDowell and Sellars on Perceptual Experience". Philosophical Books, 51 (2): 63-82.

Roessler, Johannes. 2009. "Perceptual Experience and Perceptual Knowledge". Mind 118 (472): 1013-1041. 
Draft version - please cite the official version

Sellars, Wilfred (1956) 1997. Empiricism and the philosophy of mind. Cambridge (Mass.): Harvard University Press.

Travis, Charles. Forthcoming. "The Move, The Divide, The Myth, and its Dogma". In In the Light of Experience: Essays on Reasons and Perception edited by Johan Gersel, Rasmus Thybo Jensen, Morten S. Thaning and Søren Overgaard. Oxford: Oxford University Press.

\section{Notes}

${ }^{1}$ The circumstances under which the visual presence of the cardinal will give rise to the inclination are different from the circumstances that will allow the inclined judgement to be knowledgeable. The cardinal might be in plain view and give rise to the inclination to judge without the inclined judgement being knowledgeable, if for instance the subject is placed in fake-cardinal county and by pure luck is looking at the only real cardinal amongst the thousands of seeming cardinals (compare McDowell 1998a, 390, n. 37).

2 By an unqualified use of the expression 'non-inferential' we mean non-inferential in both the epistemological and the psychological sense.

${ }^{3}$ This is how McDowell has recently treated the knowledge of a physicist who can immediately recognize a mu-meson in a cloud chamber (McDowell 2010a, 141; see also McDowell 2002, 280, and McDowell 2006a, 118).

4 Here we disagree with Roessler $(2009,1022)$ who takes McDowell's considered view to be that experiential reasons consist in the facts revealed to the subject through perception rather than the perceptual experience itself. This view, however, is explicitly dismissed by McDowell (McDowell 2006b, 134).

${ }^{5}$ This line of argument is suggested by Evans (1982), Heck (2000) and Burge (2010).

${ }^{6}$ O'Shea raises the worry that McDowell's new distinction between fundamental and non-fundamental concepts relocates rather than overcomes Davidsonian coherentism (O'Shea 2010, 81). Our worry is better expressed in terms of a danger of falling back into the Myth of the Given as it is characterized in Mind and World. 
${ }^{7}$ We thank our two anonymous reviewers for pressing us to relate our arguments regarding the first change with McDowell's second change.

${ }^{8}$ The usefulness of this distinction was suggested by one of our anonymous reviewers.

${ }^{9}$ Some further qualifications about how one relatum grounds the truth of the other must be included as any relation could be said to ensure the truth of the proposition ' $2+2=4$ '. The rough idea should be clear though.

10 Thanks to one of our anonymous reviewer for raising this issue and for suggesting a way to respond to it which we basically adopt in the following.

${ }^{11}$ Whether this is restricted to essential properties of the objects experienced depends on how finely one types experiences. One might type them in terms of time, date, and as a relation to actuality as a whole, in which case the whole state of the world would be metaphysically settled by the occurrence of the experience. This seems to be a consequence of Travis (Forthcoming) view that experience is a relation to the particular unfolding of history. However, it only strengthens our argument that we show how such an alethic relation still leaves our reasons beyond scrutiny in even the most compelling case where the type of experience merely metaphysically ensures that the experienced bird is a cardinal.

12 Recently McDowell has given up the idea that intuitional content is object-dependent (McDowell 2013, 155-156). But even with this change his position implies a strong relational view of experience because he remains committed to both the idea that experiences can constitute a truth-ensuring warrant and to the idea that amongst the judgements conclusively warranted by an intuition are judgements with object-dependent content.

${ }^{13}$ McDowell uses the terms "justify", "entitle" and "warrant" interchangeably.

${ }^{14}$ The interpretation is found in two recent publications: 'Why is Sellars's Essay called "Empiricism and the Philosophy of Mind?"' (2009b) and 'Brandom on observation' (2010a).

15 See also Evans (1982) for the role of background knowledge or what he calls 'a simple theory of perception' in supporting our perceptual capacities.

${ }^{16}$ A similar account of recognitional capacities is articulated by Millar in 'What the Disjunctivist is Right About' (Millar 2007, 192). 
Draft version - please cite the official version

${ }^{17}$ Roessler (2009) has also argued that we must conceive of perceptual knowledge as being supported in a different fashion from the ordinary conception of justification as requiring the presentation of truth-ensuring (or likelihood increasing) reasons. However, he takes perceptual justification to fall outside the scope of ordinary justification and to at best be transcendentally defended (Roessler 2009, 1032-1039). In contrast, we wish to draw attention to the fact that our ordinary practices of justifying ourselves are wider and more varied than simply presenting truth-entailing reasons. One may also draw attention to oneself and one's status as a reasonable thinker and speaker.

${ }^{18}$ See Gersel (Forthcoming) for one attempt at a McDowell inspired argument that shows why we cannot generalize the Authority Model to all perceptual knowledge.

${ }^{19}$ Crane provides a similar response to McDowell's criticism on behalf of Travis (Crane 2013, 232). 